[5] Ostensen M. The use of biologics in pregnant patients with rheumatic disease. Expert Rev Clin Pharmacol 2017;10(6):661-9.

Disclosure of Interest: None declared

DOI: 10.1136/annrheumdis-2018-eular.5162

\section{FRI0142 THE COMPARISON OF THE ULTRASONOGRAPHIC SYNOVIAL FINDINGS BETWEEN INTRAVENOUS ADMINISTRATION AND SUBCUTANEOUS INJECTION OF TOCILIZUMAB}

T. Okano $^{1}$, K. Inui ${ }^{1}$, Y. Yamada ${ }^{1}$, K. Mandai ${ }^{1}$, K. Mamoto ${ }^{1}$, Y. Sugioka ${ }^{2}$, M. Tada ${ }^{3}$, T. Koike ${ }^{2,4}, \mathrm{H}$. Nakamura ${ }^{1} .{ }^{1}$ Department of Orhopedic surgery; ${ }^{2}$ Center for Senile Degenerative Disorders (CSDD), Osaka City University Graduate School of Medicine; ${ }^{3}$ Department of Orhopedic surgery, Osaka City General Hospital, Osaka; ${ }^{4}$ Search Institute for Bone and Arthritis Disease (SINBAD), Shirahama Foundation for Health and Welfare, Wakayama, Japan

Background: Biologic disease-modifying anti-rheumatic drugs (bDMARDs) that target cytokines and cytokine receptors such as tumour necrosis factor (TNF) alpha and interleukin (IL) 6 have been established as a standard therapy in patients with rheumatoid arthritis (RA). Tocilizumab (TCZ) that targets IL-6 receptors has two administration routes such as intravenous administration (IV) or subcutaneous injection (SC). The effect of TCZ-SC therapy demonstrated comparable efficacy and safety to TCZ-IV therapy in clinical study. ${ }^{1,2}$ However, there have been no reports that evaluate the effect of TCZ-IV and SC for synovitis by imaging modality.

Objectives: The aim of this study was to compare the ultrasound findings between patients with rheumatoid arthritis (RA) treated by TCZ-IV and SC.

Methods: All patients with RA who treated with TCZ in Osaka City University RA registry (1140 patients with RA and 390 patients using bDMARDs) were included in this cross-sectional study. US examination was performed in MCP, PIP, wrist and MTP joints and finger flexor tendon and wrist extensor tendon, by using $\mathrm{HI}$ VISION Ascendus (Hitachi Medical Corporation, Japan) with a multifrequency linear transducer (18-6 MHz). The grey scale (GS) and power Doppler (PD) findings were assessed by the semi-quantitative method (0-3). GS score and PD score (both 0-156 points) were defined as the sum total of each score.

Results: We analysed total 76 patients who treated TCZ, 27 patients in IV group and 49 patients in SC group (mean age: $62.9 \pm 14.0$ vs $66.0 \pm 13.2$ years, $p=0.343$, mean duration of RA: $17.1 \pm 11.1$ vs $13.7 \pm 12.3$ years, $p=0.218)$. The duration of TCZ use was significantly longer in IV (4.6 \pm 2.2 vs $3.0 \pm 2.4$ years, $p=0.004)$. Clinically, DAS28-ESR improved from $5.3 \pm 1.5$ at baseline to $2.4 \pm 1.1$ at US examination in IV group, and it improved from $5.2 \pm 1.4$ to $2.8 \pm 1.5$ in SC group. US findings were not significantly differenced in both groups, GS score: $11.7 \pm 12.5$ vs $10.9 \pm 9.6(p=0.751)$, PD score: $5.3 \pm 8.1$ vs $5.7 \pm 6.8(p=0.832)$, max PD grade: 1.3 \pm 0.9 vs $1.4 \pm 0.9(p=0.571)$ in IV and SC respectively.

Abstract FRI0142 - Table 1. The comparison of demographic and ultrasonographic findings between TCZ-IV and SC patients with rheumatoid arthritis.

\begin{tabular}{lccc}
\hline & $\begin{array}{c}\text { TCZ-IV group } \\
(\mathrm{n}=27)\end{array}$ & $\begin{array}{c}\text { TCZ-SC group } \\
(\mathrm{n}=49)\end{array}$ & $P$ value \\
\hline Age (years old) & $62.9 \pm 14.0$ & $66.0 \pm 13.2$ & 0.343 \\
Disease duration (years) & $17.1 \pm 11.1$ & $13.7 \pm 12.3$ & 0.218 \\
Duration of TCZ use (years) & $4.6 \pm 2.2$ & $3.0 \pm 2.4$ & 0.004 \\
DAS28-ESR at baseline & $5.3 \pm 1.5$ & $5.2 \pm 1.4$ & 0.780 \\
DAS28-ESR at ultrasound examination & $2.4 \pm 1.1$ & $2.8 \pm 1.5$ & 0.175 \\
CDAl at baseline & $21.8 \pm 14.5$ & $22.8 \pm 14.4$ & 0.787 \\
CDAl at ultrasound examination & $7.3 \pm 5.9$ & $10.6 \pm 10.4$ & 0.082 \\
Total GSUS score & $11.7 \pm 12.5$ & $10.9 \pm 9.6$ & 0.751 \\
Total PDUS score & $5.3 \pm 8.1$ & $5.7 \pm 6.8$ & 0.832 \\
Maximum PDUS grade & $1.3 \pm 0.9$ & $1.4 \pm 0.9$ & 0.571 \\
\hline
\end{tabular}

Conclusions: We compared the ultrasound findings between patients with RA treated by TCZ-IV and SC. Ultrasound findings between IV and SC were not significantly differenced. Both administration routes of TCZ are effective for the treatment in patients with RA.

\section{REFERENCES:}

[1] Ogata A, Tanimura K, Sugimoto T, et al. Arthritis Care Res. 2014;66:344-

[2] Burmester GR, Rubbert-Roth A, Cantagrel A, et al. Ann Rheum Dis. 2014;73:69-74.

Acknowledgements: We wish to thank Tomoko Nakatsuka for clinical assistant, Setsuko Takeda, Emi Yamashita and Yuko Yoshida for their special efforts as a sonographer and collecting data.

Disclosure of Interest: None declared
DOI: 10.1136/annrheumdis-2018-eular.1851

\begin{tabular}{|l} 
FRI0143 \\
INFLUENCE OF LOW-DOSE GLUCOCORTICOID \\
TREATMENT ON PERSISTENCE ON BIOLOGIC DMARDS \\
THERAPY: REAL-LIFE DATA FROM THE ITALIAN GISEA \\
REGISTRY
\end{tabular}

V. Codullo ${ }^{1}$, A. Manfredi ${ }^{2}$, G. Lapadula ${ }^{3}$, E. Gremese ${ }^{4}$, A. Bortoluzzi ${ }^{5}$, E.G. Favalli ${ }^{6}$, R. Gorla ${ }^{7}$, F. Salaffi ${ }^{8}$, E. Fusaro ${ }^{9}$, R. Foti ${ }^{10}$, L. Cantarini ${ }^{11}$, A. Cauli ${ }^{12}, F$.

P. Cantatore ${ }^{13}$, A. Carletto ${ }^{14}$, F. Conti ${ }^{15}$, S. D'Angelo ${ }^{16}$, O. Epis ${ }^{17}$, R. Ramonda ${ }^{18}$

F. Atzeni ${ }^{19}$, P.C. Sarzi-Puttini ${ }^{20}$, R. Caporali ${ }^{21} .{ }^{1}$ IRCCS policlinico San Matteo Foundation, Pavia; ${ }^{2}$ University of Modena and Reggio Emilia, Modena; ${ }^{3}$ University of Bari, Bari; ${ }^{4}$ Catholic University of Sacred Heart, Rome; ${ }^{5}$ University of Ferrara, Ferrara; ${ }^{6}$ Gaetano Pini Institute, Milan; ${ }^{7}$ Spedali Civili, Brescia; ${ }^{8}$ Università Politecnica delle Marche, Jesi; ${ }^{9}$ AOU Città della Salute e della Scienza, Turin; ${ }^{10}$ Policlinico Vittorio Emanuele, Catania; ${ }^{11}$ University of Siena, Siena; ${ }^{12}$ University of Cagliari, Cagliari; ${ }^{13}$ University of Foggia, Foggia; ${ }^{14}$ University of Verona, Verona; ${ }^{15}$ Sapienza University, Rome; ${ }^{16}$ Azienda Ospedaliera Regionale "San Carlo", Potenza; ${ }^{17}$ Niguarda Hospital, Milan; ${ }^{18}$ University of Padova, Padova; ${ }^{19}$ University of Messina, Messina; ${ }^{20}$ Ospedale Sacco, Milan; ${ }^{21}$ University of Pavia, Pavia, Italy

Background: The use of glucocorticoid (GC) in Rheumatoid arthritis (RA) is recognised by the current treatment approach as a valid adjunct to DMARDs therapy. Despite its efficacy, safety of GC is still an issue and the best strategy of use is still debated, including patients under bDMARDs therapy

Objectives: To analyse in RA the differences of GC users versus non-users of baseline features, response to therapy and persistence in bDMARDs from the Italian biologics registry GISEA (Italian Group for the Study of Early Arthritis)

Methods: Consenting patients satisfying 1987 or 2010 ACR criteria for RA included in the Italian GISEA registry were enrolled. Data recorded comprehend demographic and clinimetric variables. Data are collected at baseline and 6 monthly during follow-up. To be included in the study patients needed a minimum follow-up time of 12 months and if data were not updated after 2012 patients were considered lost to follow-up. EULAR and HAQ responses were calculated. Statistical analysis included descriptive measures, parametric and nonparametric comparisons between groups and univariate analysis of survival on therapy

Results: A total of 8545 patients were enrolled, of them $4193(49 \%)$ using a variable dose of GC. In 3035 (72\%) the dose was $\leq 5 \mathrm{mg}$. Baseline demographic and disease-specific features at the start of bDMARD therapy were not different between GC users and non-users, both in 1 st and 2nd line bDMARDs RA patients. EULAR response rates were generally better in GC users at 6 and 12 months, but without statistical significance: good/moderate EULAR responses at 6 months were attained in $76,5 \%$ of GC users versus $67 \%$ in non users, while at 12 months in $81,5 \%$ vs $73 \%$ respectively (both Ps not significant). Similarly, HAQ responses $(<0.5)$ were slightly better in users vs non users at $6(42,5 \%$ vs $37,4 \%)$ and 12 months (46,5\% vs $42 \%$ ) but again without statistical significance. Finally, mean survival on bDMARDs therapy after 2 years was significantly influenced by GC with better survival curves in steroid-treated patients $(55,8 \%$ vs $47 \%$, $\mathrm{p}<0.001)$. This difference was also maintained subanalysing patients in 1 st or 2nd bDMARD lines of therapy $(56,2 \%$ in users vs $48 \%$ in non users in 1 st line and $55,3 \%$ vs $45,9 \%$ in 2 nd line, both $P$ s $<0.001$ ).

Conclusions: Our data show that GC are used in a high percentage of RA patients on bDMARD therapy. GC significantly improve the persistence on bDMARDs therapy in 1 st and 2nd line. No obvious other differences are evident in baseline, EULAR and HAQ response rates. This fact should be kept in mind when evaluating the persistence on bDMARD treatment reported in different registries. Safety evaluations in individual patients should be further analysed to guide the use of GC in this setting

Disclosure of Interest: None declared

DOI: 10.1136/annrheumdis-2018-eular.4321

\section{FRI0144 PATIENT-REPORTED OUTCOMES WITH SARILUMAB IN PATIENTS WITH RHEUMATOID ARTHRITIS ARE SIMILAR REGARDLESS OF PRIMARY OR SECONDARY FAILURE WITH TUMOUR NECROSIS FACTOR INHIBITORS}

V. Strand ${ }^{1}$, S. Boklage ${ }^{2}$, E. Mangan ${ }^{2}$, M. Reaney ${ }^{3}$, M. Iglesias-Rodriguez ${ }^{4}$, T. Kimura ${ }^{2} .{ }^{1}$ Stanford University, Palo Alto; ${ }^{2}$ Regeneron Pharmaceuticals, Inc., Tarrytown, USA; ${ }^{3}$ Sanofi, Guildford, UK; ${ }^{4}$ Sanofi, Bridgewater, USA

Background: Sarilumab is a human monoclonal antibody that binds membrane and soluble IL-6 and was recently approved for the treatment of moderate-tosevere rheumatoid arthritis. Among inadequate responders to a TNF inhibitor (TNFi), patients may respond differently to sarilumab depending on whether they had a primary $\left(1^{\circ}\right)$ failure or initially responded but then subsequently lost response (secondary $\left[2^{\circ}\right]$ failure). 
Objectives: To understand if changes in patient reported outcomes (PROs) differ among patients with $1^{\circ}$ or $2^{\circ} \mathrm{TNFi}$ failure.

Methods: In TARGET (NCT10709758), patients with intolerance or an inadequate response to TNFi were randomised to placebo or sarilumab $150 \mathrm{mg}$ or $200 \mathrm{mg}$ plus csDMARD. For patients with an inadequate response to TNFi (92\% of the sample), $1^{\circ}$ or $2^{\circ}$ failure was investigator-determined at enrollment. The following PROs were assessed at Week 0 (treatment initiation) and Week 24: HAQDI, patient global assessment of disease visual analogue scale (VAS), pain VAS, SF-36, morning stiffness VAS, EQ-5D, and Rheumatoid Arthritis Impact of Disease (RAID) scale. All scales produce global (total) scores, except the SF-36 which has eight domains and two summary scores (physical and mental component scores [PCS and MCS]) and the EQ-5D which has a single index utility score and a global health VAS. The PRO change from baseline was analysed through mixed model repeated measures with treatment, region, number of prior TNFis, baseline of the PRO analysed, visit, treatment-by-visit interaction, $1^{\circ}$ and $2^{\circ}$ subgroup, treatment-by-subgroup interaction, and treatment-by-visit-by-subgroup interaction. Post-hoc analysis of the sarilumab $200 \mathrm{mg}$ data are reported here as this is the recommended dose of sarilumab.

Results: In this post-hoc analysis, 174 of 181 patients in the placebo group and 167 of 184 in the sarilumab $200 \mathrm{mg}$ group were classified as $\mathrm{TNFi} 1^{\circ}$ or $2^{\circ}$ failures (the remaining patients were classed as intolerant or other and not included in this analysis); 75 and 64 were $1^{\circ}$ and 99 and 103 were $2^{\circ}$ treatment failures in the placebo and the sarilumab $200 \mathrm{mg}$ groups, respectively. At Week 24, changes in all $\mathrm{PROs}$ were numerically similar in the $1^{\circ}$ or $2^{\circ} \mathrm{TNFi}$ failures for both the sarilumab $200 \mathrm{mg}$ and placebo groups (table 1). Furthermore, treatment-by-subgroup interaction testing did not show a statistically significant interaction of TNFi failure status and PRO outcome (all interaction $P$-values $>0.05$ ). Treatment emergent adverse events occurred in $65.6 \%$ of sarilumab $200 \mathrm{mg}$ patients in the $1^{\circ}$ failure group and $63.1 \%$ in the $2^{\circ}$ failure group and were consistent with safety data reported previously.

Abstract FRI0144 - Table 1. Least square mean (SE) change from baseline to Week 24 in patient-reported outcomes with sarilumab $200 \mathrm{mg}$ and placebo following primary and secondary TNFi failure

\begin{tabular}{|c|c|c|c|c|c|}
\hline PRO & Placbobo & Sartitumob $200 \mathrm{mog}$ & Plocobo & $\begin{array}{l}\text { urro } \\
\text { Sarliumab } 200 \mathrm{mg}\end{array}$ & ion Pvalue" \\
\hline Pationt giobal assossmant & $\frac{(n=75)}{-2256(3.35)}$ & 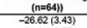 & 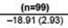 & 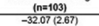 & \\
\hline $\begin{array}{l}\text { Pain vaS } \\
\text { HAD-OD }\end{array}$ & $\begin{array}{l}-21.25(3.568) \\
-0.0300098\end{array}$ & $\begin{array}{l}-31.81(3.57) \\
-0.520 .081)\end{array}$ & 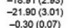 & 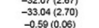 & $\begin{array}{l}0.8390 \\
0.1672 \\
0.1972\end{array}$ \\
\hline 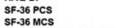 & 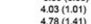 & $\begin{array}{l}8.78(1.01) \\
558(14)\end{array}$ & $\begin{array}{l}4.61(0.99) \\
484(121)\end{array}$ & 7.9510 .090 & $\begin{array}{l}0.7237 \\
0.7237 \\
\end{array}$ \\
\hline 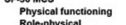 & $\begin{array}{l}4.78(1.44) \\
5: 98(2.26)\end{array}$ & 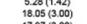 & $\begin{array}{l}4.84(1.27) \\
10.40(279)\end{array}$ & $\begin{array}{l}6.81(1,10) \\
14 \pi(2.23)\end{array}$ & $\begin{array}{l}0.0326 \\
0.2095 \\
0.059\end{array}$ \\
\hline 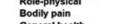 & $\begin{array}{l}9.10(3.303) \\
14.51(299)\end{array}$ & $\begin{array}{l}17.93(3.200) \\
25.353(2.93)\end{array}$ & $\begin{array}{l}11.175(2.76) \\
18.32 .63)\end{array}$ & $\begin{array}{l}20.01(2429) \\
20.02(20)\end{array}$ & $\begin{array}{l}0.0974 \\
0.8947\end{array}$ \\
\hline $\begin{array}{l}\text { Generart hestith } \\
\text { Vitatily }\end{array}$ & $\begin{array}{l}1.10(2.28) \\
0.19(2.58)\end{array}$ & 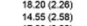 & $\begin{array}{l}7.000(21.17) \\
0.05(230)\end{array}$ & 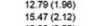 & $\begin{array}{l}0.8198 \\
0.9265\end{array}$ \\
\hline $\begin{array}{l}\text { Social turentioning } \\
\text { Role emotional }\end{array}$ & $\begin{array}{l}1293(323) \\
10.46(339) \\
1034\end{array}$ & 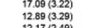 & 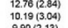 & $\begin{array}{l}1806(25.5) \\
15.55(2.22)\end{array}$ & $\begin{array}{l}0.8857 \\
0.0854\end{array}$ \\
\hline $\begin{array}{l}\text { Mentall nealth } \\
\text { FACIT-Aatigue }\end{array}$ & $\begin{array}{l}6.09(2.949) \\
7.19(1.38)\end{array}$ & 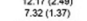 & $\begin{array}{l}9.90(2.13) \\
6.50(1.14)\end{array}$ & $\begin{array}{l}1.97(1,93) \\
10.35(1.04)\end{array}$ & $\begin{array}{l}0.5772 \\
0.1630\end{array}$ \\
\hline $\begin{array}{l}\text { Marming g vithoss VAS } \\
\text { EQ.SD VAS }\end{array}$ & $\begin{array}{l}-21.83(3.58) \\
1.72(3.32)\end{array}$ & 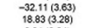 & $\begin{array}{l}-22227(1238) \\
12.51(2283)\end{array}$ & 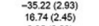 & $\begin{array}{l}0.817 \\
0.5919\end{array}$ \\
\hline 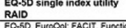 & $\begin{array}{l}0.018(0.0 .94) \\
-1.14(031)\end{array}$ & & & $\begin{array}{ll}0.3510 .039 \\
-281025\end{array}$ & \\
\hline
\end{tabular}

Conclusions: In TNFi inadequate response patients, following treatment with sarilumab $200 \mathrm{mg}+\mathrm{CsDMARD}$, changes in PRO outcomes were similar, regardless of whether they had experienced $1^{\circ}$ or $2^{\circ} \mathrm{TNFi}$ failure, suggesting that sarilumab is suitable for both $1^{\circ}$ and $2^{\circ} \mathrm{TNFi}$ failure patients.

Acknowledgements: The study was funded by Sanofi and Regeneron Pharmaceuticals, Inc.

Disclosure of Interest: V. Strand Consultant for: AbbVie, Amgen, AstraZeneca, Biogen, BMS, Celltrion, CORRONA, Crescendo, Genentech/Roche, GSK, Janssen, Eli Lilly, Novartis, Pfizer, Regeneron Pharmaceuticals Inc., Sandoz, Sanofi and UCB, S. Boklage Shareholder of: Regeneron Pharmaceuticals, Inc., Employee of: Regeneron Pharmaceuticals, Inc., E. Mangan Shareholder of: Regeneron Pharmaceuticals, Inc., Employee of: Regeneron Pharmaceuticals, Inc., M. Reaney Shareholder of: Sanofi, Employee of: Sanofi, M. Iglesias-Rodriguez Shareholder of: Sanofi, Employee of: Sanofi, T. Kimura Shareholder of: Regeneron Pharmaceuticals, Inc., Employee of: Regeneron Pharmaceuticals, Inc.

DOI: 10.1136/annrheumdis-2018-eular.3668

\section{FRI0145 A BAYESIAN NETWORK META-ANALYSIS ON EFFICACY OF BIOLOGICS AND SMALL MOLECULES IN EARLY RHEUMATOID ARTHRITIS}

V. Venerito, F. Cacciapaglia, G. Lapadula, F. lannone. Department of Emergency and Organ Transplantations, Rheumatology Unit, University of Bari "Aldo Moro", Bari, Italy

Background: The use of several biologic drugs as well as small molecules, in combination or not with methotrexate (MTX), is licensed for the treatment of Rheumatoid Arthritis (RA). Treating patients within the 'therapeutic window of opportunity' may reset the disease's long-term trajectory. Which agent would fit better the need of promptly achieving remission of patients affected with early RA is currently a matter of debate. Ideally head to head comparison are required to estimate which treatment is the most effective. Alternatively, indirect comparisons based on a common comparator may be useful. Previous indirect comparisons did not take into account all the biologics and small molecules approved for the treatment of RA, being also biassed, identifying early RA in patients with high variance of disease duration, ranging from to 6 months to 2 years.

Objectives: To provide an estimate through a Bayesian Network Meta-Analysis of which biologic or small molecule in association with MTX is more likely to determine a good clinical response in patients affected with early RA (i.e. mean disease duration $<1$ year).

Methods: A literature search was performed in accordance with the Preferred Reporting Items for Systematic Reviews and Meta-analyses (PRISMA) statement to identify results of Randomised Controlled Trials (RCTs) of biologic agents and small molecules at licensed doses to treat patients affected by early RA. MEDLINE, EMBASE, Cochrane Library, and Clinicaltrials.gov were searched for all published RCTs ranging from 1990 to September 2017. Patients had to fulfil the ACR 1988 revised criteria and/or the 2010 ACR/EULAR criteria for classified RA We included all completed RCTs of biologics or small molecules in combination with MTX, compared with MTX plus placebo or in combination with other biologics or small molecules, in patients whose RA had mean duration of less than 1 year. American College of Rheumatology (ACR) 50\% response and ACR $70 \%$ response had to be evaluated after one year of continuous treatment both in examined drug branch and in placebo branch. WinBUGS 1.4 software (MRC Biostatistics Unit, Cambridge, UK) was used to perform the analyses, using a a fixedeffect model.

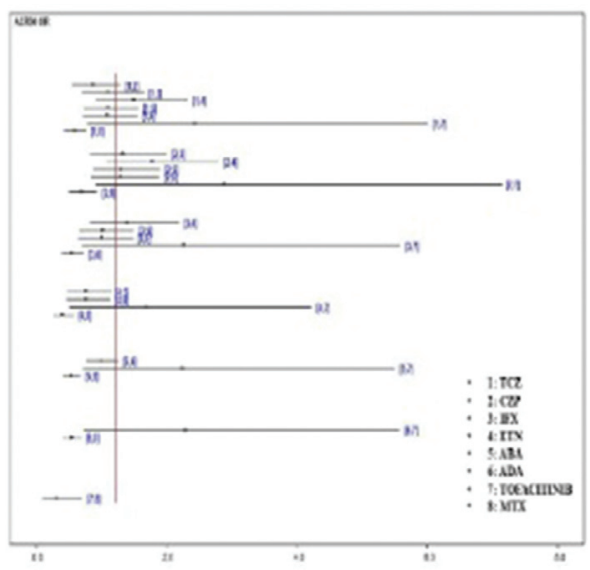

Results: Thirteen studies were included in the analysis. All the biologics as well as Tofacitinib proved to be more effective than MTX plus placebo in inducing an ACR50 response. In this regard, Tofacitib was the most effective overall (probability of being the best treatment: $75.04 \%)$ followed by Etanercept $(21.52 \%)$. The agent with the highest probability of inducing ACR70 response was Etanercep $(52.00 \%)$ followed by Abatacept $(20.22 \%)$. All compared biologics in combination with MTX were superior to MTX alone in inducing ACR70 response.

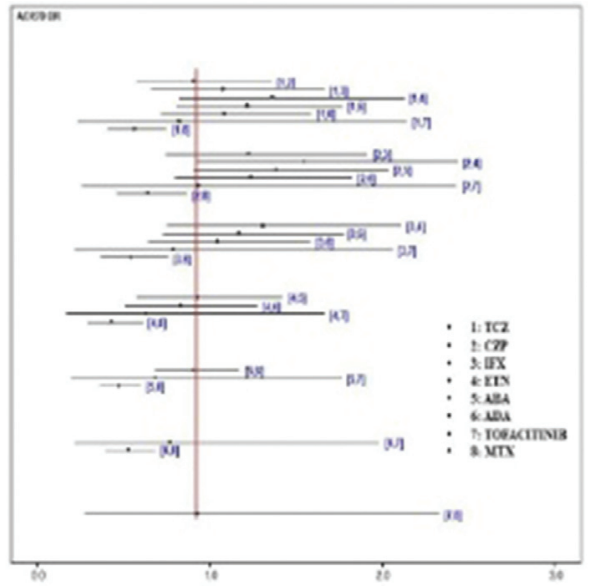

Conclusions: After one year of continuous treatment, Tofacitinib and Etanercept are the agents with the highest probability of inducing ACR50 response in patients 